\title{
Acute Atrial Fibrillation and Anaphylaxis due to Bee Sting: Case Report
}

\author{
Arı Sokması Sonucu Anaflaksi ve Akut Atrial Fibrilasyon: Olgu Sunumu
}

\author{
Ali Karakuş ${ }^{1}$, A. Burak Akçay², M. Murat Çelik³ Seçil Arıca', Veyis Taşın'1 , Koca Çalışkan \\ 'Department of Emergency Medicine, Faculty of Medicine, Mustafa Kemal University, Hatay, Turkey \\ 2Department of Cardiology, Faculty of Medicine, Mustafa Kemal University, Hatay, Turkey \\ ${ }^{3}$ Department of Internal Medicine, Faculty of Medicine, Mustafa Kemal University, Hatay, Turkey \\ ${ }^{4}$ Department of Family Medicine, Faculty of Medicine, Mustafa Kemal University, Hatay, Turkey
}

\section{ABSTRACT}

Introduction: Reactions due to bee stings ranging from local reactions to anaphylactic shock may occur in clinical presentations. Cardiac side effects and death may occur as a result of bee stings.

Case Report:This study described a 53-year-old man with no history of cardiac disorders or anaphylaxis whose lip was stung by a bee. The patient was brought to the emergency department with anaphylactic shock. There was acute atrial fibrillation shown on the electrocardiogram, and echocardiogram and biochemical markers were normal.

Conclusion: In the literature, three patients developed atrial fibrillation and atrial flutter as a result of bee stings. We also aim to share the diagnosis and treatment of such a case.

Keywords: Atrial fibrillation, bee venoms, anaphylaxis

Received: 14.09.2012 Accepted: 29.11.2012

\section{ÖZET}

Giriş: Arı sokması sonucu hastalarda lokal reaksiyonlardan anaflaktik şok ve ölüme kadar uzanan klinik tablo gelişebilir.

Olgu Sunumu: Bu yazıda 53 yaşında daha önceden herhangi bir kardiyak hastalık ve allerji öyküsü olmayan, dudağından bal arısı sokması nedeniyle anaflaktik şok ve atrial fibrilasyon gelişen hasta sunuldu.

Sonuç: Literatürde arı sokması sonucu atrial fibrilasyon ve atrial flatter gelişen üç olgu bildirilmiştir. Biz de böyle bir hastanın takip ve tedavisini paylaşmayı amaçladık.

Anahtar Kelimeler: Atrial fibrilasyon, arı venomu, anaflaksi

Geliş Tarihi: 14.09.2012 Kabul Tarihi: 29.11.2012

\section{Giriş}

Arı venomu fosfolipaz, hyaluronidaz, mellitin, karbonhidrat, biyojenik aminler, asetilkolin, lipid, aminoasit gibi maddeleri içerdiğinden lokal (ağrı, kaşıntı, ödem, kızarıklık, şş̧̧lik) ve sistemik olarak (anjioödem, karın ağrısı, bulantı, ishal, takipne, dispne, bronkospazm stridor, hırıltı, öksürük, taşikardi, aritmiler, hipotansiyon, miyokard infarktüsü ve ölüm) komplikasyonlara neden olabilir (1). Arı sokması tedavisinde soğuk uygulama ve semptomatik olarak ağrı kesiciler, soğuk uygulama, oksijen, steroidler ve epinefrin kullanılmaktadır. İntramüsküler adrenalin anafilaksi yönetiminde çok önemlidir (2). Atriyal fibrilasyon acil servislerde sık görülen bir aritmidir ancak arı sokması sonucu nadir olarak gelişebilir. Biz de böyle bir olguyu paylaşmayı hedefledik.

\section{Olgu Sunumu}

Elli üç yaşında erkek hasta, acil servise solunum güçlüğü ve bilinç değişikliği nedeniyle getirildi. Başvuru anında genel durumu kötü, glaskow koma skalası (GKS) skoru 10, kalp sesleri aritmik ve taşikardik, tansiyon arteryel değeri 60/40 mmHg, nabzı 130 atım/dakika, solunum sayısı 26/dakika, ateşi $37,5^{\circ} \mathrm{C}$. Cildi soluk ve soğuk olan hastanın diğer fizik muayene bulguları normaldi. Özgeçmişinde herhangi bir allerji veya hastalık öyküsü yoktu. 


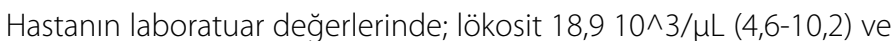
kreatin kinaz-MB (CK-MB) $26 \mathrm{U} / \mathrm{L}$ (0-24 U/L) olarak saptanırken diğer laboratuar tetkikleri normal sınırlarda idi.

Arteryel kan gazı ve göğüs radyografisinde anormallik saptanmadı. Hastanın elektrokardiyografisinde (EKG) hızlı ventrikül yanıtlı atrial fibrilasyon (AF) ve sağ dal bloğu mevcuttu (Resim 1). Hastanın bal arısı tarafından sokulduğu öğrenildi. Ciltte solukluk, hipotansiyon, taşikardi, solunum sıkıntısı ve bilinç değiş̧ikliği gelişen hastaya anaflaksi düşünülerek 0,5 mg adrenalin intramüsküler uygulandı. Ardından antihistaminik (1 ampul), prednisolon (1 mg/kg), ve oksijen (4 L/dk) tedavisi başlandı. Kardiak etkilenimin tedavisi için asetilsali- silik asit (300 mg) heparin (5000 Ü), düşük molekül ağırlıklı heparin $(0,8 \mathrm{cc})$ ve amiodaron (300 mg) yükleme tedavisi yapıldı. Adrenalin (100 cc serum fizyolojik içine 1 mg/24 saat) infüzyonu başlanan, bilinci ve vital bulguları düzelen hasta kardiyoloji servisine yatırıldı.

Kardiyoloji servisinde hastaya amiodaron infüzyonu başlandı. Hastanın yapılan ekokardiyografisinde (EKO) ejeksiyon fraksiyonu \%60 ve diğer bulguları da normal olarak tespit edildi. Hastanın kontrol kan değerleri normaldi. Amiodaron infüzyonunun 12. saatinden sonra çekilen EKG'sinde sinüs ritmi mevcuttu (Resim 2). İki gün boyunca takip edilen ve kalp ritmi normal sinüs ritmine dönen hasta paroksismal AF (ilk kez tanı alan, 48 saat içinde kendi kendine sonlanan) olarak

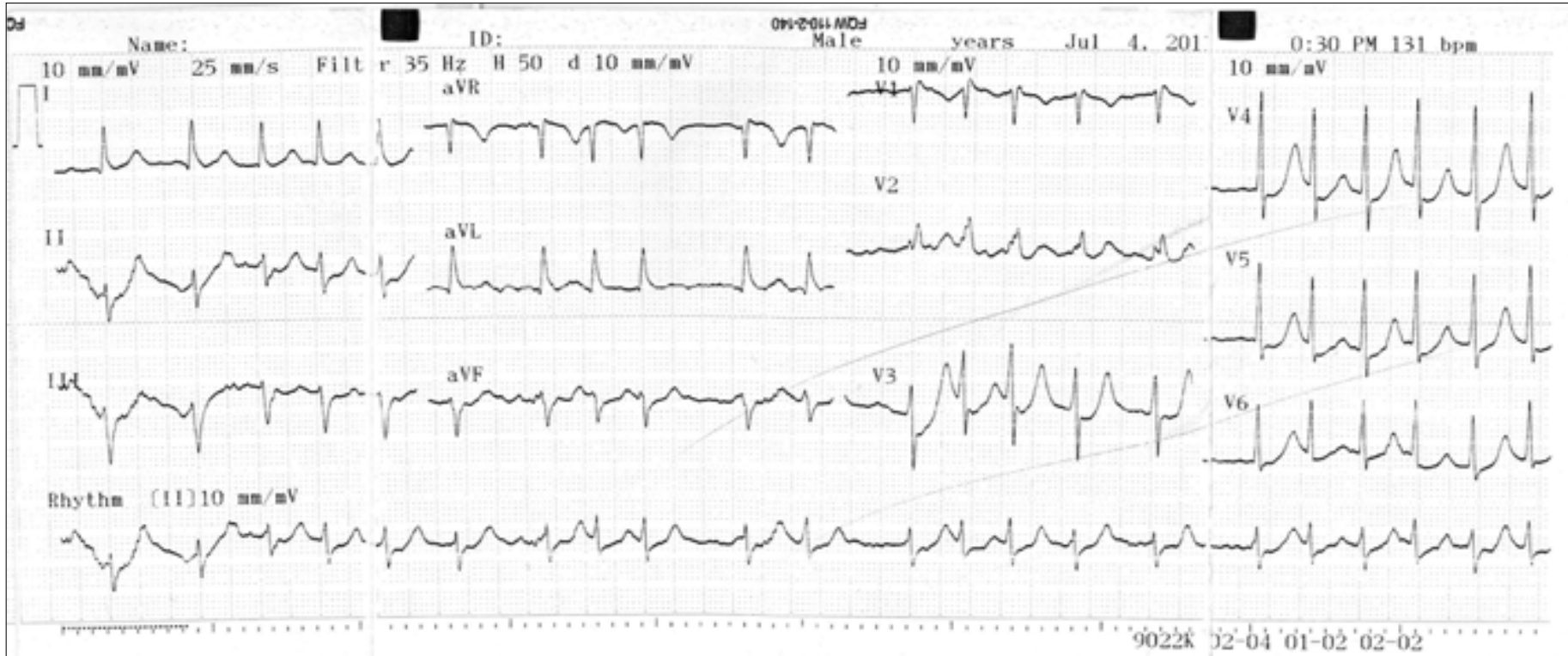

Resim 1. Hastanın acil serviste çekilen ilk elektrokardiyografisi

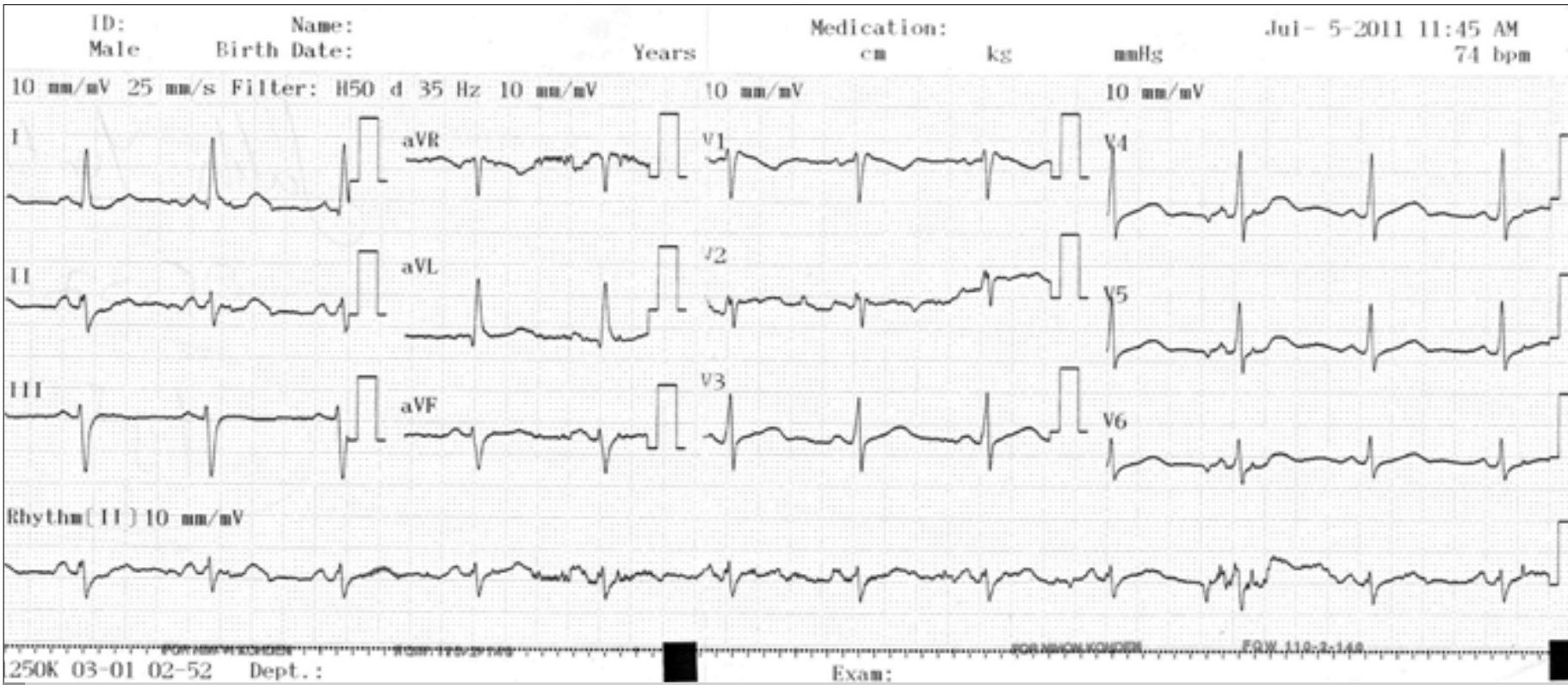

Resim 2. Hastanın amiodaron tedavisi sonrası çekilen elektrokardiyografisi 
kabul edilerek önerilerle taburcu edildi. Hastanın aylık poliklinik kontrollerinde anormallik saptanmadı. Tüm yapılan işlem ve takipler hastanın onamı alınarak planlandı.

\section{Tartışma}

Arı zehiri birçok enzim ve maddeler içerir. Bu nedenle arı sokması sonucu, lokal ve sistemik yan etkiler ortaya çıkar. Doğrudan sitotoksik etki ile koroner arteriyel vazospazm ve miyokard hasarı (veya miyokardiyal hasar) sonrası kalp etkilenimi görülebilir. Arı venomunda bulunan fosfolipaz A2, kinin ve mellitin nedeniyle endojen katekolamin salınımı artar. Hipertansiyon, karaciğer fonksiyon bozukluğu, kanama, akut böbrek yetmezliği, miyokardiyal hasar, solunum yetmezliği ve koma gibi durumlar da oluşabilir. Literatürde arı sokmasına bağlı CKMB, Troponin T (TnT) artışı ve miyokard enfarktüsü ile karakterize Kounis sendromu olarak belirtilen allerjik anjina geliştiği rapor edilmiştir $(3,4)$. Kounis sendromunun iki tipi belirlenmiş 1. tipinde normal koroner arterler mevcut iken 2. tipinde ateromatoz koroner arter hastalığı belirlenmiştir. Kounis sendromunun nedenleri arasında ilaçlar (ağrı kesici ve antibiyotikler), besin alerjisi, astım, böcek ısırmaları sayılabilir (5). Allerjen maddenin etkisi sonrasında inflamatuar yanıt, damarlarda daralma ve miyokard etkilenimi görülebilmektedir. Bizim olgumuzda ise EKG'de sağ dal bloğu ve atrial fibrilasyon mevcuttu. Kontrol EKG'lerinde ve bakılan kardiak belirteçlerde (CKMB ve Troponin I) anormallik saptanmadı.

Arı sokması sonucu özellikle duyarlı kişilerde anjioödem, anaflaktik reaksiyon ve müdahale edilmez ise ölüm görülebilir. Anaflaksi; allerjen, Immunglobulin E (lg E) yolu, mast hücresi ve bazofillerin mediatörleri ve organ etkilenimi ile sonlanır. Nedenleri arasında ilaçlar, antibiyotikler kan ürünleri tranfüzyonu, böcek sokması sayılabilir. Arı sokması sonrası \%0,4-\%5 oranında anaflaksi rapor edilmiştir. Deri, gastrointestinal sistem, solunum sistemi ve kardiovasküler sistem etkilenebilecek sistemlerdir. Hafif reaksiyonlarda kızarıklık, kaşıntı, sıcaklık hissi, orta şiddet reaksiyonda bronkospazm, larinks ödemi, nefes darlığı, göğüs ağrısı,ürtiker, senkop, nöbet, anjioödem, şiddetli reaksiyonda ise solunumsal arrest, kardiak aritmi,hipotansiyon ve şok sonrası ölüm görülebilir. Ölüm en sık solunumsal ve kardiak nedenlere bağlı olarak gelişir. Anaflaksi durumunda gerekiyorsa önce temel yaşam desteği sağlanmalı. Oksijen, adrenalin (1/1000'lik erişkinde 0,5 mg kas içi, 10-15 dakika aralarla tekrarlanabilir, çocuklarda 0,01 ml/kg kas içi), difenhidramin, prednisolon, ranitidine, sıvı veya gerekirse pozitif inotrop desteği, bronkospazmda beta-2 agonistler ve aminofilin önerilmektedir (6). Deneysel bir çalışmada Afrikan arı zehirinin ortalama arteryel basıncı ve kalp atım hızını azalttığı bildirilmiştir (7). Bir başka çalışmada arı sokması sonucu anaflaktik şok gelişen hastaların \%50'sinde ölüm görüldüğü rapor edilmiştir (8). Takip edilen olguda arı sokması sonrası gelişen anaflaktik şok tablosu ve kardiak aritmi mevcuttu. Hastanın uygun ve zamanında müdahale ile tedavisi sağlandı.

Atrial fibrilasyon (AF), atriyal kökenli düzensiz bir ritimdir. AF nedenleri arasında aort ve pulmoner kapak hastalığı, perikardit, miyokardit, sistemik ve pulmoner hipertansiyon, hipoksi, pnömoni, subaraknoid kanama, hipertiroidi, alkol ve karbonmonoksit zehirlenmesi, elektrik çarpması sayılabilir (9). Ancak \%30 olguda herhangi bir neden sap- tanamayabilir. AF'ye müdahale edilmediği durumlarda komplikasyon olarak konjestif kalp yetmezliği, kardiyomiyopatiler ve sistemik emboli gelişebilmektedir (10). Literatürde nadir bir neden olarak arı sokması sonrası AF, atrial flatter ve ventriküler fibrilasyon gelişen üç olgu bildirilmiştir $(11,12)$. Takip ettiğimiz olguda mevcut olan yüksek ventrikül yanıtlı $A F$, medikal tedavi sonrası sinüs ritmine döndü ve hasta önerilerle komplikasyon gelişmeksizin taburcu edildi.

\section{Sonuç}

Arı sokması sonucu anaflaktik şok ve kardiyak etkilenim görülebilir. Klinik tablo miyokard infarktüsü ile benzer olup uygun tanı ve müdahalede gecikme durumunda hastalık ölümle sonuçlanabilir. Ani gelişen anaflaksi, kardiak etkilenim veya ölüm durumunda arı sokması gibi nedenler akılda tutulmalıdır. Bu tür hastalar aritmi ve miyokard etkilenimi açısından erken dönemde monitorize edilip uygun tedaviye başlanmalıdır.

Conflict of Interest: No conflict of interest was declared by the authors.

Peer-review: Externally peer-reviewed.

Informed Consent: Written informed consent was obtained from patient who participated in this case.

Author Contributions: Concept - A.K.; Design - A.K., M.M.Ç.; Supervision - A.B.A., M.M.Ç., S.A.; Funding - A.K., M.M.Ç., S.A.; Materials - A.K., A.B.A., V.T., K.Ç.; Data Collection and/or Processing - A.K., A.B.A.; Analysis and/or Interpretation - A.K.; Literature Review - A.K., S.A., V.T., K.Ç.; Writer - A.K.; Critical Review - A.B.A., M.M.Ç.

Financial Disclosure: The authors declared that this study has received no financial support.

Çıkar Çatışması: Yazarlar çıkar çatışması bildirmemişlerdir.

Hakem değerlendirmesi: Dış bağımsız.

Hasta Onamı: Yazılı hasta onamı bu olguya katılan hastadan alınmıştır.

Yazar Katkıları: Fikir - A.K.; Tasarım - A.K., M.M.Ç.; Denetleme - A.B.A., M.M.Ç., S.A.; Kaynaklar - A.K., M.M.Ç., S.A.; Malzemeler - A.K., A.B.A., V.T., K.Ç.; Veri toplanması ve/veya işlemesi - A.K., A.B.A.; Analiz ve/veya yorum - A.K.; Literatür taraması - A.K., S.A., V.T., K.Ç.; Yazıyı yazan - A.K.; Eleştirel İnceleme - A.B.A., M.M.Ç.

Finansal Destek: Yazarlar bu çalışma için finansal destek almadıklarını beyan etmişlerdir.

\section{Kaynaklar}

1. Ciszowski K, Mietka-Ciszowska A. Hymenoptera stings. Przegl Lek 2007; 64: 282-9.

2. Jevon P. Severe allergic reaction: management of anaphylaxis in hospital. Br J Nurs 2008; 17: 104-8. 
3. Mytas DZ, Stougiannos PN, Zairis MN, Tsiaousis GZ, Foussas SG, Hahalis GN, et al. Acute anterior myocardial infarction after multiple bee stings. A case of Kounis syndrome. Int J Cardiol 2009; 134: 29-31. [CrossRef]

4. Raper RF, Fisher MM. Profound reversible myocardial depression after anaphylaxis. Lancet 1988; 1: 386-8. [CrossRef]

5. Gluvic ZM, Putnikovic B, Panic M, Stojkovic A, Milutinovic ZR, Gavrilovic JJ. Acute coronary syndrome in diclofenac sodium-induced type I hypersensitivity reaction: Kounis syndrome. Malta Medical Journal 2007; 19: 3.

6. Kalpaklıoğlu AF. Insect Allergy. Allergy Asthma Immunology 2003; 1: 44-53

7. Guimaraes JV, Costa RS, Machado BH, dos Reis MA. Cardiovascular profile after intravenous injection of Africanized bee venom in awake rats. Rev Inst Med Trop Sao Paulo 2004; 46: 55-8. [CrossRef]
8. De Sousa L, Vásquez D, Salazar D, Valecillos R, Vásquez D, Rojas M, et al. Human mortality due to invertebrate and vertebrate envenomation in Monagas State, Venezuela. Invest Clin 2005; 46: 241-54.

9. İcer M, Gulactı U, Dursun R. Elektrik carpmasına bağlı gelişen atrial fibrilasyon. JAEM 2012; 3: 129-31. [CrossRef]

10. Oto A. Diagnosisand treatment guidlines Turkish society of cardiology atrial fibrillation. Archive of Turkish Society of Cardiology 2003; 31: 737-62.

11. Okutucu S, Şabanov C, Abdulhayoğlu E, Aksu NM, Erbil B, Aytemir K, et al. A rare cause of atrial fibrillation: A European hornet sting - Case Report. The Anatolian Journal of Cardiology 2011; 11: 559-60.

12. Wojtowicz M, Biernat C. Case of ventricular fibrillation following a bee sting. Pol Tyg Lek 1976; 31: 2229-30. 